\title{
Grammar Games: A Case for Instructionist Game Models to Enhance Grammar Awareness and Accuracy
}

\author{
Brian Raftery I Jennifer Santos
}

A few years ago - on the other side of the world - Beth Herbert began an article about grammar games by relating a story of a colleague who, new to teaching, was observed by a supervisor while giving a lesson about grammar (Hebert, 2012). At the conclusion of the lesson, the young teacher's supervisor tried to redirect her efforts, explaining that "grammar was no longer to be explicitly taught" (Herbert, 2012, p. 21). The setting of the story-Australia-and the time in which it occurred-the 1970s-may seem far removed from today's educational experiences. But they are not. Indeed, some publications now seek to instruct teachers in grammar (Behrens \& Mercer, 2011) and one of the authors of this article was trained in the current millennium to teach English without discussing grammar. This is the educational background shared by many current students (Thomas \& Austin, 2005) and "this means teachers in multiple disciplines often encounter grammatical problems with student writing and those teachers report that they feel ill-equipped to address these issues even as they recognize the importance of helping students practice grammatically-correct writing practices" (Raftery \& Santos, 2014).

Indeed, teachers and students alike often feel frustrated when faced with the grammar and punctuation that serve as the foundation of written communication (Carduner, 2007; Mei-Yun \& Tzu-Fu, 2008). This frustration can be compounded when grammar must be addressed in non-English classes or in developmental writing classes where students bring varying competencies to the class. One example of these varying competencies might be envisioned via the source of grammatical errors. Rustick (2007) argues, "Though some errors are due to a lack of explicit knowledge, many effective student writers cannot explain the rules while others, including nonnative speakers who have learned traditional grammar, know the rules but cannot apply them" (p. 46). Based on our own experiences teaching grammar in developmental writing classes and classes not dedicated to writing instruction, along with a history of scholarship that indicates a need for grammar pedagogies (e.g., Dougherty, 2012), instructor-designed grammar games can likely help facilitate learning about these mechanics of writing while easing the frustrations of grammar instruction. Ultimately, the versatility of grammar games in assessing student learning (e.g., launch or review) makes them valuable tools for educators in any field that requires writing.

\section{WHY GAMES? WHY GRAMMAR GAMES?}

Most work with games in college classes includes an apology, of sorts, for games generally, justifying why an instructor might take valuable time to "play." Perhaps the most common defense has to do with student engagement: Matas and Natolo (2011) see games as combining "learning and enjoyment" (p. 372); Thomas and Austin (2005) situate games as a "hook," titling their article "Fun with fundamentals" to reinforce the point (p. 65). Indeed, as Kafai (2006) has observed, most work on games focuses on the "motivational or social aspects of playing games for learning" (p. 37). Student engagement is valuable and Matas and Natolo's (2011) broad, international study of traditional educational models does indict models that omit engagement by revealing that "two-thirds of their teenagers [from 32 different nations] were bored in class" (p. 371). However, it may be beneficial to see a grammar game as more than just a fun hook. Rustick (2007) is correct to remind educators that "Increasing student engagement, as difficult as that might be, is only part of the problem. The real challenge is changing the way we think about sentencelevel issues, which requires tremendous fortitude" (p. 45). Traditionally, this fortitude has involved a combination of rote memorization of rules and exercises, thus establishing a dichotomy between drills and the engaged learner. (It is hoped that Kempen's observation that "grammar instruction cannot restrict itself to conveying grammatical insights to the students" (1999, p. 10) will be obvious to pedagogically-inclined readers.) 
This dichotomy is only one of many in discussions of grammar education. Linguists continue to debate whether grammar and usage should be considered conjoined (e.g., Jones, Myhill, \& Bailey, 2013; Newmeyer, 2003), a dichotomy closely related to prescriptive and descriptive perspectives on grammar (e.g., Myhill \& Watson, 2014). Likewise, compositionists and educators discuss the source of grammatical errors as either a deficit or part of a learning process (e.g., Rose, 1985). All the while, English teachers continue to grapple with the relationship between spoken and written language, notwithstanding the typical separation of speech classes and writing classes into Communication departments and English departments, respectively (e.g., Rustick, 2007). Even journals outside the field of language studies have published work on the conflicting nature of grammar acquisition (e.g., Dove, 2012). Yet from a learner-centered perspective, these professional and intellectual differences, often described "through the metaphor of battle and grammar wars" (Myhill \& Watson, 2014, p. 41), mean little. Students at a variety of institutions, from honors students to developmental writers, simply say to us "grammar is important, but grammar is confusing" or "I'm just not good at grammar."

For these students, professional and theoretical dichotomies are irrelevant and secondary to the students' own feelings of confusion and frustration. Interestingly, Myhill and Watson's recent review (2014) of grammar pedagogy literature, quite thorough in most respects, includes sections on theoretical perspectives and teacher perspectives but conspicuously omits student perspectives. Many students have learned that they need to be able to use grammar (and punctuation) but perceive themselves to be hopeless. Engagement, then, may not simply be about making learning fun; rather, engagement may involve bringing students themselves into the conversation and introducing them to debates about the utility of grammar rules. From this perspective, it also includes the fortitude Rustick (2007) associates with grammar itself and a safe space to develop this fortitude is necessary ( $p$. 45).

For students who have "given up" on grammar, those who see writing courses as "not for me" or "hopeless," games may open a space for discussion that other pedagogical techniques may not. In the course of a well-designed game, students can gain the practice so essential to the grammar awareness valued by many grammar pedagogues (Myhill \& Watson, 2014) while also engaging in their own debates about the mechanics of the English language, reflecting on their responses and the responses of "opposing teams." Bender's work (2003) suggests that a "process of deliberation not only helps . . . understanding and self-correction, but also assists in reinforcing long-term memory" (p. 21). It is this process of deliberation that grammar games can help students explore. In short, these games can help students to become learners.

\section{GAMES AND LEARNING: INSTRUCTIONIST VS. CONSTRUCTIONIST MODELS}

In the last ten years, the impetus to increase grammatical awareness and fortitude has been addressed by a constructionist approach to grammar games (another of the many dichotomies of grammar instruction, pitting constructionist approaches against instructionist approaches). In this model, educators now favor student-designed grammar games to increase "the student-centred focus of a game-based approach to grammar learning" (Matas \& Natolo, 2011, p. 373). The early research shows that student empowerment can be added to the engagement, reflection and collaborative benefits of instructor-designed games (Matas \& Natolo, 2011). Pedagogies centered on student-designed games have gained enough momentum that groups are hard at work "developing new programming environments that facilitate the media-rich manipulation needed for game design" (Kafai, 2006, p. 38 ) to enable students to create more complex and technologically-rich games.

The possibilities of constructionist games as pedagogical tools for a number of aspects of English studies are intriguing. However, given the effects of grammar wars on students, it is prudent to be concerned about privileging constructionist games over instructionist games during grammar and punctuation learning opportunities for two reasons: (1) grammar instruction is most successful when placed in the context of writing (Myhill \& Watson, 2014) and (2) grammar learning is not a linear process (Rustick, 2007), which makes expert-driven direction and review crucial.

The first point-that grammar instruction works best in the context of writing - is crucial for 
students, not only to establish "buy in" with an immediate application of knowledge (perhaps to an upcoming writing assignment) but also to establish what Myhill and Watson (2014) call "a role for grammar in the writing curriculum as a functionally oriented endeavor" (p. 54). It is in this space of function that theoretical perspectives on grammar instruction can re-align with the practical needs of students. Such an alignment seems a difficult prospect when faced with the practicality of devoting class time-or writing time - to a student developed grammar game (although it is possible to envision a reflective writing assignment joined with the construction of the game that may mitigate this concern for one writing assignment). In contrast, carefully-designed and thoughtfully-presented instructionist grammar games may minimize the practical issue of seat time devoted to the game, may be more easily contextualized for students as crucial to an upcoming essay or a review for peer editing and may offer the same possibilities for practice and reflection. Indeed, some instructionist grammar games can even offer students a venue for the empowerment benefit typically seen in constructionist games by encouraging students to discuss and/or defend their responses that lend themselves to grammatical awareness.

Grammatical awareness is likewise crucial to the second reason for urging educators who teach grammar to retain instructionist game design as a part of grammar pedagogy: grammar learning is not a linear process (Rustick, 2007); it requires direction. Perhaps one of the most frustrating challenges for students learning grammar and punctuation is that "the ability to control surface features of writing does not progress linearly; errors students seem to have mastered often reappear when they take on more complex writing tasks" (Rustick, 2007, p. 46). Research on the disappearance and reappearance of grammatical errors is not just anecdotal, nor is it simply self-reported; in 1994, Redington and Chater completed work on guessing games and artificial learning constructions that inverted the formula of assessing "correct" answers, instead assessing a movement toward learning based on establishing places of what they term "ignorance" (p. 745). Examining what learners do not yet know - or do not currently recall-about the artificial grammar, these authors conclude that the experiment "support[s] the hypothesis that frag- ment knowledge plays an important part in artificial grammar learning" (p. 745). These fragments of knowledge are what college-level developmental writing teachers most often encounter with students, especially in classes where foreign-language speakers are in classes with native speakers who struggle with grammatical rules.

These fragments can also be a source of frustration for students who expect a linear progression and who often notice slips after progression. In our experience, making students aware of the non-linear process and helping students to recognize where a fragment of knowledge got lost or is needed, proves crucial to learning and maintaining the fortitude required to develop enhanced grammatical awareness. Instructionist grammar games allow teachers to do just that. In contrast, according to Kafai (2006), constructionist models reject "embedding 'lessons' directly in games" in favor of encouraging students to "construct new relationships with knowledge in the process" (p. 38) of creating a game. While activities that encourage students to create their own relationships with knowledge are laudable, embedded lessons can help fill gaps in grammar knowledge (and, perhaps, usage). Thus, when dealing with mechanics of the English language, it could be useful to retain instructionist grammar games that guide students in joining together their fragments of knowledge while also designed to offer a space for discussion and reflection that encourages forming the new relationships with knowledge that enhance grammatical awareness.

\section{USING GRAMMAR GAMES}

There are numerous grammar games published for English-language learners and for K-12 (e.g., Mario Rinvoucri's, 1984, Grammar Games: Cognitive, affective and drama activities for EFL students, now in its 29th reprinting). Some are stealth "work books"; others do collect games that are variously individual, collaborative and/or competitive. Some are exploratory and others seek correct/incorrect answers. One especially effective type of grammar game is inspired by Jeopardy ${ }^{\mathrm{TM}}$ because the game board format offers a means of asking different types of questions, allows for collaboration and good-natured competition and fosters discussion. It can also be used in small and large classes alike, a consideration of increasing importance as the trend to large-classroom composition sections grows. 
A typical game goes something like this: the instructor reviews the subject matter of the game and ask students to make connections to an upcoming writing assignment. The instructor then review the rules:

1. The class plays in teams.

2. The first team is selected by a coin toss. The first person to correctly answer the instructor's coin toss question (e.g., related to an upcoming campus event or deadline) earns the right for his/her team to go first.

3. The class proceeds through each team and question in a clockwise manner.

4. The first team must choose a category and level.

5. All students must carefully listen to the question; it is on an overhead screen and will be read aloud twice.

6. All students must be prepared to answer the question.

7. If the class and instructor judge the team's answertobesatisfactory, the followinghappens: a. The team who satisfactorily answers the question wins the point value of the question. b. A team who wins points on their question selects the category (but not the level for the team that follows, moving in a clockwise direction).

8. Partial credit may be awarded by class vote or instructor discretion.

9. In the event of an incorrect or partially correct answer, the following happens: a. If one team's answer is (or is voted) incorrect, a second team may "buzz in." One representative per team must be elected to raise his/her hand to serve as a buzzer. The first hand in the air gets a chance to collect points from a question that has not yet been answered to the class' satisfaction. b. If the team's question is not answer correctly in full, that team may not select the category for the team that follows.

10. The class keeps score but plays in the spirit of learning and comradery.

Following the rules review, the class divides into teams. In small classes that already have collaboration teams, students play in their usual groups. In large classes (we have played this type of grammar game with classes of 75 students), smaller groups are assigned to play with their "quadrant of the room": northwest, northeast, southwest and southeast. Each team elects a spokesperson for a "coin toss," which typically relates to an upcoming event on campus. The first correct answer wins the toss and, in consultation with their teammates, selects the first category and level of a question. After being presented with the question, all teams are given time to consult. When the team has reached consensus, the class listens to the answer and rationale presented.

It is at this point that reflection, deliberation and new knowledge can be formed. Teams with an objection can voice their opinions and engage in spirited discussions. As facilitators, instructors sometimes play devil's advocate and award partial points for particularly engaged grammatical awareness. As the game progresses around the room, the questions allow students to practice the grammatical concepts they have previously covered and continue to discuss the implications of "choices" and "rules." It can be especially useful to include different types of questions with different levels of "correctness" to help foster these discussions, but grammar games can also be a valuable tool in a classrooms that is not precisely focused on writing by using university writing center sources as the basis for questions. It may also be worth nothing that a Jeopardy-inspired grammar game also has the advantage of helping instructors: it requires minimal technological savvy and a single game can serve as a template for future games.

\section{CODA: ADAPTING GRAMMAR GAMES TO THE ONLINE AND NON-ENGLISH CLASSROOM}

With this essay, a template is included that can be adapted for a variety of questions; it can be used effectively in online classes or non-English classrooms as a launch or review activity that relates to course content. By designing the game questions to test not only grammar knowledge and skills but also understanding of the subject under study, instructors in virtual and traditional classrooms can accomplish two learning objectives at the same time. In the sample game included in this essay, the questions test rudimentary knowledge of social psychology, but they just as easily could have been written for virtually any other subject. The game could be played as a launch activity to reactivate stored knowledge of grammar and social psychology or as a review activity to revisit important terms 
and concepts. In online classrooms, questions could be posted in discussion forums, enabling students to earn participation points for answering and discussing the questions. In online classrooms with a synchronous component, the game could be used to enliven a Skype session and played in much the same way as in a traditional classroom environment. Regardless of the course delivery method, these lessons have the potential to enrich the educational experience of our learners. To test this hypothesis, empirical research should be undertaken that compares the learning outcomes of students in classes that incorporate instructionist games and those that do not.

In the continuing debate between instructionist and construction pedagogies, the former is to be preferred when it comes to the creation of grammar games for use in English and non-English classes. Instructionist grammar games can motivate students to find connections between their fragments of knowledge. This approach provides opportunities for discussion and reflection that encourage the formation of new relationships with knowledge, thus enhancing grammatical awareness. In addition, instructor-designed grammar games facilitate learning about the mechanics of writing while easing the frustrations of grammar instruction. Ultimately, the versatility of grammar games in assessing student learning (e.g., launch or review) makes them valuable tools for educators in any field that requires writing.

\section{REFERENCES}

Behrens, S. \& Mercer, C. (2011). Syntactic boundaries and the mechanics of written English: A workshop for teachers. Research \& Teaching in Developmental Education, 28(1), 50-56.

Bender, T. (2003). Discussion-based online teaching to enhance student learning. Sterling, VA: Stylus.

Carduner, J. (2007). Teaching proofreading skills as a means of reducing composition errors. Language Learning Journal, 35(2), 283-295. doi 10.1080/09571730701317655

Doughtery, E. (2012). Moving from "teaching grammar" to teaching the process of editing: Summaries + queries. Research \& Teaching in Developmental Education, 29(1), 50-55.

Dove, G. (2012). Grammar as developmental phenomenon. Biology \& Philosophy, 27(5), 615-637. doi:10.1007/s10539-0129324-4
Feldman, R. S. (2013). Psychology and your life. (2nd ed.). New York, NY: McGraw-Hill.

Herbert, B. (2012). Grammar games: A practical guide to teaching grammar in context. Practically Primary, 17(1), 21-24.

Jones, S., Myhill, D., \& Bailey, T. (2013). Grammar for writing?: An investigation of the effects of contextualised grammar teaching on students' writing. Reading \& Writing, 26(8), 1241-1263. doi: 10.1007/s11145-012-9416-1

Kafai, Y. B. (2006). Playing and making games for learning: Instructionist and constructionist perspectives for game studies. Games and Culture, 1(1), 36-40. doi:10.1177/1555412005281767

Kempen, G. (1999). Visual grammar: Multimedia for grammar and spelling instruction. In K. Cameron (Ed.), CALL: Media, design and applications (pp. 223-238). Lisse: Swets \& Zeitlinger. Retrieved from http://www.mpi.nl/publications/ escidoc-1082661.

Matas, C. P., \& Natolo, M. (2011). Love grammar: Student-driven grammar learning games. The International Journal of Learning, 17, 371-382.

Mei-Yun, K., \& Tzu-Fu, W. (2008). Teacher talk in grammar instruction: A sociocultural perspective. International Journal of Learning, 15(5), 271-280.

Myhill, D., \& Watson, A. (2014). The role of grammar in the writing curriculum: A review of the literature. Child Language Teaching and Therapy, 30(1), 41-62. doi:10.1177/0265659013514070

Newmeyer, F. T. (2003). Grammar is grammar and usage is usage. Language, 79(4), 682-707.

Raftery, B., \& Santos, J. (2014, June). Comma sense: Grammar games for online and traditional classes. Paper presented at Grand Canyon University's Center for Innovation in Research and Teaching's Online Teaching Showcase. Retrieved from https://cirt.gcu.edu/teaching3/ots/otspresentations.

Redington, M., \& Chater, N. (1994). The guessing game: A paradigm for artificial grammar learning. In Proceedings of the sixteenth annual meeting of the cognitive science society (pp. 745-749). Hillsdale, NJ: Lawrence Erlbaum Associates. Retrieved from http://www.dectech.co.uk/publications/LinksNick/Language/The $\% 20$ guessing $\% 20$ game $\% 20 \% 20 \mathrm{~A} \% 20$ paradigm $\% 20$ for $\% 20$ artificial\%20grammar\%20learnin.pdf.

Rinvoucri, M. (1984). Grammar games: Cognitive, affective and drama activities for EFL students. Cambridge, UK: Cambridge University Press. 
Rose, M. (1985). The language of exclusion: Writing instruction at the university. College English, 47(4), 341-359.

Rustick, M. T. (2007). Grammar games in the age of anti-remediation. Journal of Basic Writing, 26(1), 43-62.

Thomas, K. M., \& Austin, M. (2005). Fun with fundamentals: Games and electronic activities to reinforce grammar in the college writing classroom. Teaching English in the Two-Year College, 33(1), 62-69.

\section{About the Authors}

Brian Raftery is a cum laude graduate of St. John's University and the recipient of a teaching fellowship to Syracuse University, where he earned a Master's Degree in English and American Literature while teaching composition classes. In 2010, he joined Grand Canyon University's full-time English faculty. He has supervised the full-time online English faculty and is currently serving as content lead for the ground English faculty. He has served as Subject Matter Expert for several literature and composition courses. He has published articles in Current Biography on the poets James Merrill, Galway Kinnell and Seamus Heaney. In 2014, he co-presented at the Two-Year College Association's Western Region Conference, which was sponsored by the National Council of Teachers of English.

Dr. Jennifer M. Santos is an Assistant Professor in Grand Canyon University's College of Humanities and Social Sciences where she teaches developmental writing, first-year composition, honors classes and graduate classes. She has published peer-reviewed articles and book chapters on visual rhetoric, audience studies and best practices for writing pedagogy. In 2010, she was awarded a research grant by the National Endowment for the Humanities. Dr. Santos was recently elected by her peers to the executive committee of the Modern Language Association's Present-Day English Discussion Group. 